\section{PERCEPÇÃO SOCIAL SOBRE GESTÃO AMBIENTAL EM ASSENTAMENTOS RURAIS NO NORTE DO PARANÁ E NO PONTAL DO PARANAPANEMA}

Luiz Antonio Norder Maurício Ventura Ursi ${ }^{2}$

ReSumo: Este texto apresenta os resultados de uma pesquisa quantitativa realizada a partir de questionários estruturados, aplicados em amostragem aleatória, que abrange as regiões do Pontal do Paranapanema (SP) e do Norte do Paraná, com a finalidade de caracterizar a percepção de assentados e técnicos extensionistas sobre os serviços de extensão e alguns componentes de gestão ambiental: tratamento de esgoto, resíduos sólidos, erosão, assoreamento, embalagens de agrotóxicos e arborização de espaços habitados. Foram também incluídas informações sobre percepções de qualidade habitacional. A pesquisa evidencia que, embora haja a identificação, por parte de assentados e extensionistas, de diversos problemas ambientais nos assentamentos, predomina a percepção de que há uma grande limitação nas ações de extensão rural voltadas para estes problemas.

Palavras-Chave: Gestão Ambiental; Gestão de Resíduos; Recursos Hídricos; Estudos de Percepção; Assentamentos Rurais.

ABSTRACT: This paper presents the results of a quantitative survey based on structured questionnaires applied at a random and representative sampling in areas of land settlements in the regions of Pontal do Paranapanema (SP) and Northern Paraná. The objective is characterize the perception of settlers and technical extension services about some components of environmental management: sanitary sewer, domestic waste, erosion, siltation, empty pestination containers, and arborization of inhabited spaces. Information about housing quality perceptions was also included. The survey shows that there is the identification by settlers and extension of environmental problems related to theses components, but also predominate the perception

'Professor do Departamento de Desenvolvimento Rural da Universidade Federal de São Carlos (DDR/UFSCar) E-mail: luiz.norder@cca.ufscar.br.

${ }^{2}$ Professor do Departamento de Agronomia da Universidade Estadual de Londrina (UEL).E-mail: mventura@uel.br that there is a strong limitation in the rural extension of actions for these problems.

KEYwords: Environmental Management; Wast Management; Hidric Resources; Perception Studies; Land Settlements.

\section{INTRODUÇão}

Nos últimos anos, diversas pesquisas vêm buscando analisar as múltiplas dimensões do processo histórico de assentamento de populações em áreas rurais através de programas de reforma agrária, distribuição de terras públicas, criação de reservas extrativistas, programas de crédito fundiário e outras políticas fundiárias. Ao mesmo tempo, as políticas públicas passaram a priorizar os processos de desenvolvimento rural com base em enfoques territoriais. Inclui a complexidade do debate ambiental e seus aspectos sociais, culturais, educacionais, políticos, institucionais, jurídicos, estéticos, paisagísticos, entre outros. Tendo em vista a relevância do envolvimento e da participação dos diversos atores nos processos de transição ambiental em áreas rurais e urbanas, diversas pesquisas vêm sendo realizadas com a finalidade de avaliar a percepção social em relação a diversas temáticas, como veremos na próxima seção.

Neste sentido, este artigo analisa, especificamente, as percepções de assentados sobre quatro componentes de gestão ambiental: tratamento de esgoto doméstico, resíduos sólidos, recursos hídricos e arborização do espaço habitado. Foram selecionadas as regiões do Pontal do Paranapanema e do Norte do Paraná, onde foi realizada pesquisa quantitativa por amostragem aleatória, com a aplicação de questionário estruturado, como veremos abaixo. Na região do Pontal do Paranapanema, foi também possível levantar dados sobre a percepção de extensionistas da Fundação Itesp, o que permitiu uma análise comparativa com a percepção dos assentados da mesma região.

Os dados foram produzidos no âmbito do Projeto de Pesquisa Avaliação Participativa e Indicadores de ATER em Agroecologia e Restauração Florestal em Assentamentos Rurais no Pontal do Paranapanema (SP) e no Norte do Paraná (PR), financiado pelo CNPq e realizado por docentes do Departamento de Desenvolvimento Rural da Universidade Federal de São Carlos (UFSCar) e do Departamento de Agronomia da Universidade Estadual de Londrina (UEL) e estudantes das duas instituições. As duas regiões pesquisadas apresentam histórico de conflitos sociais pela posse da 
terra e atuação de movimentos sociais, sobretudo a partir dos anos 90, com expressiva mobilização política com vistas à realização de programas de reforma agrária (CECÍLIO; PUZIOL; SILVA, 2010;). A partir de 2005, os movimentos sociais e a criação de assentamentos nas duas regiões passaram, no entanto, por um expressivo refluxo.

No que se refere à questão ambiental, na região Norte do Paraná, pesquisas recentes apontam para a complexidade do processo social de constituição dos assentamentos rurais, considerando sua localização, fertilidade do solo e formas de organização interna (TSUKAMOTO; ASARI, 2003), em um contexto regional marcado por uma rápida e intensa devastação florestal a partir da década de 1930 (SANTOS FILHO, 1980). No Pontal do Paranapanema, a degradação ambiental provocada pelo desordenado e predatório processo histórico de ocupação se expressa, mais recentemente, na forma como vem sendo praticada a pecuária extensiva, na construção de barragens de usina hidrelétricas, no assoreamento dos rios e córregos e em intensos processos de perda dos solos (erosões e voçorocas), o que tem mobilizado diferentes instituições na busca de soluções (BARONE; FERRANTE, 2012).

\section{FundamentaÇão Teórica}

A pesquisa realizada parte de referenciais teóricos sobre desenvolvimento territorial rural e estudos de percepção social, que serão abordados nas próximas duas seções.

\section{Desenvolvimento Territorial Rural}

A partir do final dos anos 1990, as teorias sobre desenvolvimento rural passaram a atribuir maior relevância ao conceito de território como eixo de interpretação analítica e política (BONNAL; MALUF, 2009). Chegase mesmo a estabelecer uma contraposição entre, por um lado, a noção de desenvolvimento agrícola, centrado em categorias econômicas e setoriais, e, por outro, a noção de desenvolvimento rural, centrado na categoria território (HUYLENBROECK; DURAND, 2003). Desta forma, as conceituações sobre desenvolvimento rural passam a ser apresentadas como uma ruptura em relação às teorias sobre a modernização da agricultura - e também como um novo paradigma simultaneamente de pesquisa e de políticas públicas (PLOEG, 2006).

Neste sentido, há uma revalorização do rural enquanto espaço habitado, como suporte para o desenvolvimento de múltiplas atividades não agrícolas e como depositário da biodiversidade e da agrobiodiversidade (LEFF, 2009). O rural passa então a ser interpretado em sua multidimensionalidade, passando pela qualidade de vida de seus habitantes, pela diversificação econômica, pela presença de uma infra-estrutura moderna e pela preservação ambiental, entre outros aspectos. Para tanto, ganha relevo as formas de articulação social e políticas dos diversos atores em um determinado território (MIOR, 2003) ou em determinada transição agroambiental (BRANDENBURG, 2004).

Este deslocamento no foco interpretativo esteve associado a uma releitura sobre a importância da agricultura familiar e do campesinato, tendo em vista o repertório cultural, os interesses específicos e as práticas sociais e organizativas de uma diversificada população rural que busca autonomia e qualidade de vida (WANDERLEY, 2001). Os assentamentos rurais, derivados de variadas políticas de distribuição fundiária, inserem-se em um heterogêneo conjunto de iniciativas voltadas para o estabelecimento de diversidades que caracterizam os processos de desenvolvimento rural (CUNHA; NUNES, 2008; COSTA; FUTEMMA, 2006).

\section{Estudos de Percepção Social}

Trata-se de uma abordagem que, mantendo suas especificidades metodológicas, remete à utilizada pelo Instituto de Pesquisa Econômica Aplicada (IPEA) em seu Sistema de Indicadores de Percepção Social (SIPS), cuja finalidade é produzir "indicadores sociais que possibilitem verificar como a população avalia os serviços de utilidade pública disponíveis ou postos à disposição pelo Estado brasileiro" (SCHIAVINATTO, 2011: 253). Neste sentido, o estudo do IPEA contém estudos de percepção social sobre acesso à Justiça, igualdade de gênero, direito das crianças, saúde, educação, cultura, inclusão financeira, trabalho e renda.

Os estudos de percepção têm sido utilizados, portanto, em diversas áreas de conhecimento, como apoio à formulação de políticas ambientais (RODRIGUES et al., 2012), em regiões com riscos ambientais derivados de atividades de mineração (VALENTE, 2008), em educação ambiental (MARIN, 2008), entre outras.

"A literatura sobre a percepção social de riscos naturais e tecnológicos é relativamente abundante e tem conhecido, ao longo dos últimos anos, um aumento significativo, sobretudo no que se refere à forma como as diversas percepções sociais são (ou não) integradas em processos de tomada de 
decisão e em medidas associadas à prevenção, mitigação e eliminação dos riscos" (VALENTE, 2008: 3)

As informações quantitativas derivadas de estudos de percepção podem contribuir para a qualificação do debate público sobre diversos temas e têm sido reconhecidas como um instrumento para a identificação de demandas, caracterização de problemas e mapeamento de limitações na implementação de políticas públicas. Também permitem dimensionar determinadas características educacionais e culturais, bem como sua transformação ao longo do tempo.

\section{Metodologia da Pesquisa}

A pesquisa realizada em assentamentos nas regiões Norte do Paraná e Pontal do Paranapanema teve o objetivo de produzir informações quantitativas de percepção social através da aplicação de questionário estruturado em amostragem aleatória e representativa.

As famílias foram selecionadas previamente, tendo como base a numeração oficial dos lotes, de acordo com a Fundação Instituto de Terras de São Paulo (Itesp) e o Instituto Nacional de Colonização e Reforma Agrária (INCRA). As questões e respostas com múltipla escolha contemplaram temas como qualidade de vida e trabalho, produção agropecuária e agroecológica, gestão ambiental, restauração de florestas nativas e avaliação sobre os serviços de Assistência Técnica e Extensão Rural (ATER), entre outros, de forma a obter dados referentes ao ano-base de 2010.

Foram utilizados os parâmetros estatísticos da Pesquisa Sobre Qualidade de Vida, Produção e Renda nos Assentamentos do Brasil (PQRA), publicada pelo INCRA (Instituto Nacional de Colonização e Reforma Agrária) em 2010, cuja amostragem de 2,0\% permitiu o estabelecimento de uma margem de confiança de $95 \%$ para os resultados obtidos (INCRA, 2010).

Na região do Pontal do Paranapanema, formada por 32 municípios, vários deles entre os mais baixos IDHs do Estado de São Paulo, considerou-se um universo de 5.707 famílias assentadas, distribuídas em 108 projetos de assentamentos criados pelos governos federal e estadual até 2005, em uma área total de 138.681 hectares, o que perfaz uma média de aproximadamente 24 hectares por família; os assentamentos pesquisados existiam há pelo menos dez anos; em todos os casos, os serviços de assistência técnica e extensão rural vinham sendo prestados pela Fundação Itesp.

O questionário estruturado foi aplicado junto a uma amostra de 2,45\% dos lotes (22\% acima da utilizada na PQRA/INCRA), totalizando 140 famílias entre 13 de abril e 07 de maio de 2011 em 85 assentamentos situados em 14 municípios: Caiuá, Euclides da Cunha Paulista, Marabá Paulista, Martinópolis, Mirante do Paranapanema, Piquerobi, Presidente Bernardes, Presidente Epitácio, Presidente Venceslau, Rancharia, Rosana, Sandovalina, Teodoro Sampaio e Ribeirão dos Índios.

Os Escritórios Regionais da Fundação Itesp e o total de famílias e de assentamentos assistidos no momento da pesquisa eram os seguintes: Mirante do Paranapanema, 1.156/30; Presidente Bernardes: 589/12; Presidente Epitácio: 390/5; Presidente Venceslau: 1.072/22; Rosana: 628/4; Euclides da Cunha: 662/11; e Teodoro Sampaio: 1.210/24. Assentamentos com um pequeno número de famílias não foram incluídos no plano amostral por não terem sido sorteados; é o caso de assentamentos com menos de 30 famílias; ainda assim, foi mantida a proporção em pequenos assentamentos em relação ao total. O mesmo ocorreu para os assentamentos pesquisados no Paraná.

No Norte do Paraná, foram selecionados três municípios contíguos, caracterizados por uma população majoritariamente rural e com predominância de atividades agropecuárias: Ortigueira, São Jerônimo da Serra e Tamarana. Estes três municípios contavam em 2010, respectivamente, com populações de 23.554 (59\% rural), 11.336 (50\% rural) e 12.232 habitantes (52\% rural). Trata-se de uma região que apresentava os mais baixos IDH (Índice de Desenvolvimento Humano) no Paraná em 2000, sendo que o município de Ortigueira apresentou o mais baixo IDH $(0,620)$ no Estado. Os municípios de São Jerônimo da Serra e Tamarana, com IDHs de 0,674 e 0,683, situavam-se entre os 25 municípios com o menor IDH no Estado, que contava com 399 municípios (IPARDES, 2003).

Dados oficiais do INCRA/PR indicavam um total de 520 famílias em sete assentamentos em Ortigueira, 282 famílias em onze assentamentos em Tamarana e 339 famílias em oito assentamentos em São Jerônimo da Serra, todos estes criados havia mais de dez anos. Os serviços de assistência técnica e extensão rural vinham sendo ofertados desde 2008 mediante convênio entre o INCRA e a Emater/PR (Instituto Paranaense de Assistência Técnica e Extensão Rural) - e realizados por esta em parceria com a Fundação Terra. A Fundação Terra é uma Organização da Sociedade Civil de Interesse Público (Oscip), conforme Lei 9.790/99, criada em 2002 em uma Assembleia Geral Extraordinária da Associação dos Funcionários 
da Emater/PR. Foram aplicados 71 questionários entre 09 e 14 de maio de 2011 em 20 assentamentos nos três municípios paranaenses selecionados, correspondendo a $6,2 \%$ do total de famílias assentadas - uma amostragem, portanto, três vezes superior à utilizada na PQRA/INCRA (2010).

Foi também realizada a aplicação de um questionário estruturado junto aos técnicos extensionistas da Fundação Itesp na região do Pontal do Paranapanema, com parte das questões elaborada de forma similar às apresentadas aos assentados. Isso permitiu uma comparação com a percepção dos assentados em relação a diversos assuntos. Foram obtidos 56 questionários preenchidos de um total de 83 profissionais da Fundação Itesp atuando com ATER (Assistência Técnica e Extensão Rural) na região do Pontal do Paranapanema, o que corresponde a $67,4 \%$ do total. As questões também foram realizadas tomando 2010 , como ano-base.

Os principais resultados da pesquisa sobre a região do Pontal do Paranapanema foram discutidos presencialmente em atividade realizada no município de Teodoro Sampaio no âmbito da programação Itesp Debate, em 12 de julho de 2012, que contou com a participação de aproximadamente 50 pessoas, entre coordenadores e técnicos extensionistas e representantes de assentados e movimentos sociais. A atividade evidenciou que a construção de indicadores de percepção em escala regional, como os que serão analisados a seguir, contribui significativamente para o debate público sobre o planejamento e as ações de assistência técnica e extensão rural.

\section{RESUlTAdOS DA PESQUiSA}

Apresentaremos nesta seção os resultados da pesquisa, inicialmente com informações relevantes para uma contextualização dos indicadores relacionados às agências oficiais de ATER nos dois Estados pesquisados. Em seguida, há uma análise das condições sociais e habitacionais, incluindo uma comparação com a situação anterior ao assentamento. As seções seguintes permitem caracterizar a percepção dos assentados sobre as condições de tratamento de esgoto doméstico, destinação de resíduos sólidos, recursos hídricos e arborização do espaço habitado.

\section{Contextualização}

É preciso salientar, inicialmente, que a percepção dos assentados sobre os serviços de ATER, analisada a seguir, pode ser interpretada a partir de seu contexto local e regional. Dados obtidos pela pesquisa mostram que há diferentes percepções em relação às vinculações institucionais estabelecidas pelos assentados. As vinculações mais frequentemente consideradas positivas eram as que vinham sendo estabelecidas com o comércio local, com agências bancárias e com entidades religiosas. Com prefeituras, as vinculações foram consideradas ótimas ou boas por $26 \% \mathrm{e}$ $28 \%$, respectivamente, no norte do Paraná e no Pontal do Paranapanema.

Cerca de um terço afirmava que vinha mantendo vinculações boas ou ótimas com a Fundação Itesp, órgão estadual responsável pelos serviços de extensão rural no Pontal do Paranapanema; por outro lado, outros 28,6\% as apresentavam como ruins ou péssimas, o que se configura como uma percepção um pouco mais favorável do que aquela manifestada em relação às prefeituras da região (NORDER, URSI, MENEZES JR, 2014).

Tabela 1- Percepções sobre a qualidade dos serviços de ATER no Norte do Paraná e no Pontal do Paranapanema (2010).

\begin{tabular}{|c|c|c|c|c|c|c|}
\hline & $\mathrm{N}$ & Ótima & Boa & Regular & Ruim & Péssima \\
\hline Assentados no Norte do & 69 & 4,35 & 23,19 & 24,64 & 17,39 & 30,43 \\
\hline $\begin{array}{l}\text { Paraná } \\
\text { Assentados no Pontal do } \\
\text { Paranapanema (SP) }\end{array}$ & 136 & 2,94 & 18,38 & 29,41 & 19,12 & 30,15 \\
\hline Técnicos Itesp (SP) & 69 & 8,93 & 55,36 & 33,93 & 1,79 & - \\
\hline
\end{tabular}

Fonte: Norder, Ursi, Menezes Jr., 2014.

É preciso levar em conta que apenas 5\% dos assentados do Pontal do Paranapanema e por $11 \%$ dos assentados no Norte do Paraná afirmaram ter participado de atividades de extensão realizadas por organizações nãogovernamentais, universidades e outras instituições foram identificadas (para maiores detalhes, ver NORDER, URSI, MENEZES JR, 2014). A pesquisa também gerou dados e análises sobre gestão florestal (NORDER et al., 2015) e transição agroecológica (NORDER et al., 2017).

\section{CONDIÇÕES SOCIAIS E HABITAÇÃ̃o}

As Tabelas 2 e 3 mostram que, para a maioria dos assentados nas duas regiões pesquisadas, as melhorias mais significativas estão relacionadas à qualidade da habitação e da alimentação. Em seguida, aparecem a renda e o patrimônio familiar. No caso do Norte do Paraná, 64,7\% dos assentados consideram que sua habitação no assentamento era melhor do que a 
anterior, contra $28 \%$ que indicavam uma piora neste aspecto. Por volta de $45 \%$ dos assentados nesta região estimavam ter ocorrido uma melhoria na educação, na saúde, no patrimônio coletivo e nas condições de esporte e lazer. Informações complementares podem ser observadas na Tabela 2.

Tabela 2- Percepção dos assentados sobre situação social antes e depois do assentamento na região Norte do Paraná (2010).

\begin{tabular}{lcccc}
\hline Norte do Paraná & $\mathrm{N}$ & Melhor & Igual & Pior \\
\hline Moradia & 68 & 64,7 & 7,35 & 27,94 \\
Educação & 64 & 46,88 & 21,88 & 31,25 \\
Saúde & 70 & 44,29 & 27,14 & 28,57 \\
Renda & 69 & 56,52 & 27,54 & 15,94 \\
Alimentação & 68 & 54,41 & 33,82 & 11,76 \\
Organização & 55 & 40,00 & 32,73 & 27,28 \\
Esporte e lazer & 60 & 46,67 & 36,67 & 16,66 \\
Patrimônio familiar & 67 & 55,22 & 31,34 & 13,43 \\
Patrimônio produtivo & 65 & 40,00 & 49,23 & 10,77 \\
Patrimônio coletivo & 45 & 53,33 & 35,56 & 11,11 \\
\hline
\end{tabular}

Fonte: Pesquisa de Campo, 2011.

A Tabela 3 mostra que, entre $50 \%$ e $60 \%$ dos assentados da região Norte Paranaense, o total de cômodos e a qualidade da casa onde viviam eram avaliados como bom ou ótimo, em contraposição a aproximadamente $20 \%$ que as consideravam ruim ou péssimo. Em relação ao saneamento básico, $25 \%$ manifestaram a percepção de que a situação era ruim ou péssima, predominando, no entanto, para mais de $70 \%$, a percepção de que as condições de saneamento eram boas ou razoáveis - aspecto que voltará a ser discutido adiante.

Tabela 3 - Percepção dos assentados sobre condições de moradia no Norte

\begin{tabular}{lcccccc}
\multicolumn{7}{c}{ do Paraná (2010). } \\
\hline Norte do Paraná & N & Otimo & Bom & Razoável & Ruim & Péssimo \\
\hline Total de cômodos & 71 & 12,68 & 49,30 & 21,13 & 12,68 & 4,23 \\
Qualidade da casa & 71 & 5,63 & 46,48 & 26,76 & 12,68 & 8,45 \\
Saneamento básico & 71 & 1,41 & 43,66 & 29,58 & 18,31 & 7,04
\end{tabular}

Fonte: Pesquisa de Campo, 2011.

Na região do Paranapanema, a percepção de que houve uma melhoria em termos habitacionais, alimentares e financeiros, entre outros aspectos, é ainda mais intensa do que a verificada no Norte do Paraná. Por outro lado, há também a avaliação de que o acesso aos serviços públicos de saúde e as opções de esporte e lazer estão entre os fatores menos favoráveis, ainda que, como mostra a Tabela 4, predomine, nestes mesmos quesitos, a percepção de que com o assentamento houve uma melhoria generalizada das condições de vida.

Tabela 4 - Percepção dos assentados sobre situação social antes e depois do assentamento na região do Pontal do Paranapanema (2010)

\begin{tabular}{lcccc}
\hline Pontal do Paranapanema & $\mathrm{N}$ & Melhor & Igual & Pior \\
\hline Moradia & 140 & 74,28 & 13,57 & 12,14 \\
Educação & 124 & 55,65 & 29,03 & 15,32 \\
Saúde & 138 & 44,92 & 28,99 & 26,09 \\
Renda & 139 & 64,03 & 25,90 & 10,07 \\
Alimentação & 138 & 68,12 & 27,54 & 4,35 \\
Organização & 119 & 60,50 & 31,09 & 8,40 \\
Esporte e lazer & 129 & 42,64 & 22,48 & 34,88 \\
Patrimônio familiar & 137 & 60,58 & 33,58 & 5,84 \\
Patrimônio produtivo & 130 & 50,77 & 36,92 & 12,31 \\
Patrimônio coletivo & 110 & 52,73 & 39,09 & 8,18 \\
\hline
\end{tabular}

Fonte: Pesquisa de Campo, 2011.

Em relação ao Pontal do Paranapanema, preponderou a percepção, presente em mais de $70 \%$ dos assentados pesquisados, de que o total de cômodos e a qualidade geral da habitação eram bons ou ótimos; e a identificação de problemas de saneamento básico apenas em um pequeno grupo de assentados, cerca de $13 \%$ do total (Tabela 5).

Tabela 5 - Percepção dos assentados sobre condições de moradia no Pontal

\begin{tabular}{lcccccc}
\multicolumn{7}{c}{ do Paranapanema (2010). } \\
\hline Total de cômodos & 139 & Ótimo & Bom & Razoável & Ruim & Péssimo \\
Qualidade da casa & 139 & 12,58 & 50,36 & 21,58 & 5,76 & 0,72 \\
Saneamento básico & 134 & 5,97 & 56,04 & 29,50 & 10,07 & 2,16 \\
\hline
\end{tabular}

Fonte: Pesquisa de Campo, 2011.

A Tabela 6 disponibiliza os dados sobre acesso à comunicação nos assentamentos das duas regiões estudadas. Destaca-se a reduzida 
inclusão digital, com apenas 4,23\% e 7,14\% dos domicílios pesquisados, respectivamente, do Norte do Paraná e do Pontal do Paranapanema com computadores com internet e uma cobertura de telefonia celular de aproximadamente $78 \%$ nas duas regiões.

Tabela 6- Acesso a comunicações nos assentamentos no Norte do Paraná e no Pontal do Paranapanema (2010).

\begin{tabular}{lcc}
\hline & $\begin{array}{c}\text { Pontal do Paranapanema } \\
(\mathrm{N}=140)\end{array}$ & $\begin{array}{c}\text { Norte do Paraná } \\
(\mathrm{N}=71)\end{array}$ \\
\hline Computador com internet & $7,14 \%$ & $4,23 \%$ \\
Telefonia celular & $77,14 \%$ & $78,87 \%$ \\
Telefonia fixa & $10,00 \%$ & - \\
Telefone público & $6,43 \%$ & $36,62 \%$ \\
\hline
\end{tabular}

Fonte: Pesquisa de Campo, 2011.

Predominou entre os assentados a avaliação de que as ações das agências de Assistência Técnica e Extensão Rural (ATER) para a melhoria das condições habitacionais foi nula ou prejudicial, tanto no caso da Emater no Norte do Paraná como da Fundação Itesp no Pontal do Paranapanema. Apenas uma parcela de aproximadamente $12 \%$ dos assentados nas duas regiões, com pequenas variações, reconhecia as ações realizadas como excelentes ou boas. Já entre os técnicos extensionistas da Fundação Itesp, a percepção era de que as ações para a melhoria habitacional haviam sido boas, o que corresponde a dois terços do total, como consta na Tabela 7 .

Tabela 7 - Avaliação de assentados e técnicos sobre a contribuição da Agência de ATER para a melhoria nas condições de habitação em assentamentos rurais (2010).

\begin{tabular}{lcccccc}
\hline & $\mathrm{N}$ & Excelente & Boa & Insuficiente & Nula & Prejudicial \\
\hline Norte do Paraná & 70 & - & 11,43 & 2,86 & 71,43 & 14,29 \\
Pontal do Paranapanema & 140 & 1,43 & 10,71 & 8,57 & 71,43 & 7,86 \\
Técnicos do Itesp & 56 & 16,07 & 66,07 & 14,29 & 3,57 & - \\
\hline
\end{tabular}

Fonte: Pesquisa de Campo, 2011.

\section{Tratamento DE ESGOTO DOMÉSTICO}

Nos assentamentos pesquisados tanto no Norte do Paraná quanto no Pontal do Paranapanema não foi identificada a instalação de rede de coleta pública de esgoto em 2010. Os dados da Tabela 8 mostram que a fossa negra (ou fossa simples), segundo a pesquisa, era a destinação dos dejetos humanos em $92 \%$ dos assentamentos do norte do Paraná e em $78 \%$ da amostra do Pontal do Paranapanema. Já a fossa séptica estava presente, de acordo com a percepção dos assentados pesquisados, em apenas 1,41\% dos lotes no Norte do Paraná e em 18,71\% no Pontal do Paranapanema. Junto a isso, havia o lançamento de dejetos (de origem humana ou animal) em 19,7\% dos lotes dos assentamentos do Norte do Paraná e 9\% dos lotes no Pontal do Paranapanema, segundo a percepção dos assentados.

Tabela 8 - Percepção dos assentados sobre destinação de dejetos sanitários em assentamentos no Norte do Paraná e no Pontal do Paranapanema (2010).

\begin{tabular}{lccccccc}
\hline & $\mathrm{N}$ & $\begin{array}{c}\text { Rede de } \\
\text { esgoto }\end{array}$ & $\begin{array}{c}\text { Fossa } \\
\text { séptica }\end{array}$ & $\begin{array}{c}\text { Fossa } \\
\text { negra }\end{array}$ & $\begin{array}{c}\text { Fossa } \\
\text { simples }\end{array}$ & $\begin{array}{c}\text { Não } \\
\text { tem }\end{array}$ & $\begin{array}{c}\text { Rios, } \\
\text { Riachos }\end{array}$ \\
\hline $\begin{array}{l}\text { Norte do } \\
\text { Paraná }\end{array}$ & 71 & - & 1,41 & 64,79 & 28,17 & 5,63 & - \\
$\begin{array}{l}\text { Pontal do } \\
\text { Paranapanema }\end{array}$ & 139 & - & 18,71 & 64,75 & 15,11 & 0,71 & 0,72 \\
\hline
\end{tabular}

Fonte: Pesquisa de Campo, 2011.

A Tabela 9 mostra que a ação das agências de ATER para a melhoria do esgotamento sanitário foi avaliada como nula por $76 \%$ das famílias do Norte do Paraná e por 76,3\% no pontal do Paranapanema.

Tabela 9 - Avaliações sobre as ações de ATER para melhoria dos sistemas de esgotamento sanitário em assentamentos no Norte do Paraná e no Pontal do Paranapanema (2010).

\begin{tabular}{lcccccc}
\hline & $\mathrm{N}$ & Excelente & Boa & Insuficiente & Nula & Prejudicial \\
\hline Assentados Norte do Paraná & 71 & 1,41 & 2,82 & 2,82 & 76,06 & 16,90 \\
Assentados no Pontal & 135 & 1,48 & 5,93 & 5,93 & 76,30 & 10,37 \\
Paranapanema & 55 & 1,82 & & 27,27 & 47,27 & 3,64 \\
Técnicos do Itesp no Pontal & 55 &
\end{tabular}

Fonte: Pesquisa de Campo, 2011

No Norte do Paraná, 16,9\% consideravam que as ações chegaram a ser prejudiciais; e no Pontal, 10,37\%. Apenas 4,23\% no Norte do Paraná avaliaram as ações nesse sentido como excelentes ou boas. No Pontal do Paranapanema apenas 7,94\% afirmaram que foram excelentes ou boas. Mesmo entre técnicos do ITESP participantes da pesquisa, 47,3\% 
avaliaram as ações para esta finalidade como nulas; para outros $27,3 \%$, foram insuficientes e para 3,6\%, prejudiciais. As ações para tratamento de esgoto doméstico foram consideradas como excelentes ou boas por $21,82 \%$ dos técnicos extensionistas.

\section{DESTINAÇÃO DE RESÍDUOS SÓLIDOS}

A pesquisa sobre gestão de resíduos permitiu um levantamento de dados sobre destinação de diversos resíduos sólidos: plástico, papel, vidro, alumínio, pilhas e baterias, óleo de cozinha, óleos e fluidos de motores e veículos, rejeitos, embalagens de agrotóxicos e entulhos de construção civil.

No caso dos assentamentos selecionados na região Norte do Paraná, a coleta regular ou a comercialização destes resíduos estava circunscrita a apenas uma minoria das famílias. De acordo com os resultados da pesquisa, os resíduos recicláveis vinham sendo, predominantemente, enterrados, queimados ou depositados a céu aberto, contra 5,2\% que afirmaram comercializar ou entregar em um sistema de coleta regular. Cerca de dois terços $(67,2 \%)$ afirmaram que pilhas e baterias vinham sendo queimadas, enterradas, depositadas a céu aberto ou em cursos d'água. Outras informações obtidas pela pesquisa podem ser observadas na Tabela 10 .

Tabela 10 - Destinação de resíduos em assentamentos no Norte do Paraná (2010).

\begin{tabular}{lcccccl}
\hline Tipo de Resíduo & $\mathrm{N}$ & $\begin{array}{c}\text { Coleta/ } \\
\text { Venda }\end{array}$ & $\begin{array}{c}\text { Queimado/ } \\
\text { Enterrado }\end{array}$ & Enterrado & $\begin{array}{c}\text { Céu } \\
\text { aberto }\end{array}$ & Rios \\
\hline Plástico, papel, & 58 & 5,20 & 18,97 & 55,17 & 24,14 & - \\
vidro, alumínio & 58 & 10,87 & 18,97 & 32,76 & 12,07 & 3,45 \\
Pilhas e Baterias & 18 & 24,72 & 27,78 & 38,89 & 11,11 & - \\
Óleo de cozinha & 49 & 2,51 & 8,16 & 8,16 & - & 2,04 \\
Óleo de motor, & 66 & 3,52 & 15,16 & 62,12 & 22,73 & - \\
fluidos veículos & Rejeitos & 16,38 & 8,00 & 2,00 & - & - \\
Entulho. Demolição & 50 & &
\end{tabular}

Fonte: Pesquisa de Campo, 2011.

Na região do Pontal do Paranapanema, a coleta regular ou comercialização de resíduos alcançou índices superiores aos verificados no Paraná. Ainda assim, $88,4 \%$ dos assentados afirmaram que resíduos recicláveis, como plástico, papel, vidro e alumínio, vinham sendo queimados, enterrados ou depositados a céu aberto ou lançados em cursos d'água; no caso específico de pilhas e baterias, o descarte no interior do próprio lote ou em cursos d'água chegava a, aproximadamente, dois terços do total $(65,5 \%)$. Aproximadamente $11 \%$ dos assentados afirmaram que vinham depositando óleos e fluidos de motores, equipamentos e veículos no interior do próprio lote ou em cursos d'água. Outras informações sobre a destinação de resíduos, na percepção de assentados da região do Pontal do Paranapanema, podem ser observadas na Tabela 11.

Tabela 11- Destinação de resíduos em assentamentos no Pontal do Paranapanema (2010).

\begin{tabular}{lcccccc}
\hline Tipo de Resíduo & $\mathrm{N}$ & $\begin{array}{c}\text { Coleta/ } \\
\text { Venda }\end{array}$ & $\begin{array}{c}\text { Queimado/ } \\
\text { Enterrado }\end{array}$ & Enterrado & $\begin{array}{c}\text { Céu } \\
\text { aberto }\end{array}$ & Rios \\
\hline $\begin{array}{l}\text { Plástico, papel, vidro, } \\
\text { alumínio }\end{array}$ & 121 & 14,81 & 11,57 & 50,41 & 25,62 & 0,83 \\
Pilhas e Baterias & 122 & 16,34 & 30,33 & 25,41 & 8,20 & 1,64 \\
Óleo de cozinha & 41 & 36,34 & 24,39 & 24,39 & 9,76 & - \\
Óleo de motor & 82 & 5,13 & 3,66 & 3,66 & - & 3,66 \\
Rejeitos & 132 & 11,47 & 9,85 & 68,18 & 13,64 & - \\
Entulho, demolição & 108 & 18,35 & 12,96 & 1,85 & 3,70 & - \\
\hline
\end{tabular}

Fonte: Pesquisa de Campo, 2011.

As ações de ATER no ano de 2010 para aprimorar o tratamento destes resíduos nos assentamentos foram avaliadas como excelentes ou boas por apenas 7,25\% da amostragem no Norte do Paraná e por 4,57 \% no Pontal do Paranapanema. Outros 4,35\% no Norte do Paraná e 5,07\% no Pontal do Paranapanema as consideravam insuficientes; $14,5 \%$ no norte do Paraná e $13,77 \%$ no Pontal do Paranapanema consideravam que as ações teriam sido prejudiciais. Cerca de três em cada quatro assentados nas duas regiões avaliaram como nulas as ações de ATER para a gestão de resíduos. Entre os técnicos extensionistas da Fundação Itesp, os que consideravam as ações de ATER para a gestão de resíduos como insuficientes ou nulas chegou a 78\% do total. Informações adicionais sobre avaliação de assentados e extensionistas em relação à gestão de resíduos podem ser encontradas na Tabela 12.

Dados gerados pela pesquisa mostram que, entre os extensionistas do Itesp no Pontal do Paranapanema, menos do que $2 \%$ afirmaram ter trabalhado "muito" com gestão de resíduos e outros $35 \%$ consideravam ter trabalhado 
"razoavelmente", ou seja, pouco mais que um terço do total;

Tabela 12 - Avaliações de assentados e técnicos do Itesp sobre as ações de ATER para gestão de resíduos em assentamentos no Norte do Paraná e no Pontal do Paranapanema (2010)

\begin{tabular}{lllllll} 
& $\mathrm{N}$ & Excelentes & Boas & Insuficientes & Nulas & Prejudiciais \\
\hline Assentados no Norte PR & 69 & - & 7,25 & 4,35 & 73,91 & 14,49 \\
Assentados no Pontal & 138 & 0,72 & 3,62 & 5,07 & 76,81 & 13,77 \\
Técnicos do Itesp no & 56 & 3,57 & 17,86 & 53,57 & 25,00 & - \\
Pontal & & & & & & \\
\hline
\end{tabular}

Fonte: Pesquisa de Campo, 2011.

37\% consideravam que haviam atuado "pouco" ou "muito pouco" c o m a gestão de resíduos. Os que responderam que não tiveram qualquer envolvimento com esta temática somavam 19,6\% dos extensionistas no Pontal do Paranapanema.

A grande maioria dos assentados nas duas regiões, mais de $80 \%$ do total, considerava que não houve atuação das respectivas agências de ATER para o aprimoramento da destinação de embalagens de agrotóxicos. Havia, no entanto, uma diferença entre as duas regiões: no Pontal do Paranapanema, 7,6\% identificaram ações efetivas do escritório de ATER para aprimorar a destinação de embalagens de agrotóxicos, além de 9,16\% que identificaram "muito poucas" ações neste sentido; já nos assentamentos dos municípios selecionados no Norte do Paraná, o total de assentados que identificou ações efetivas de ATER oficial para a gestão de resíduos chegou a 16,67\%. Para os servidores da Fundação Itesp no Pontal do Paranapanema, as ações dos escritórios regionais voltadas para um aprimoramento na destinação de embalagens de agrotóxicos foram consideradas excelentes ou boas por $62,5 \%$ dos assentados, contra $16 \%$ que as consideravam nulas e $21,43 \%$ insuficientes.

\section{RECURSOS HÍDRICOS}

A disponibilidade de água para uso doméstico foi estimada como suficiente por $90 \%$ dos assentados no Norte do Paraná e no Pontal do Paranapanema. A principal fonte de abastecimento no Pontal eram poços artesianos ou semiartesianos $(72,1 \%)$, seguidos de poço cacimba $(22,9 \%)$, nascentes $(2.14 \%)$ e rede pública. A cloração desta água vinha sendo realizada por $17 \%$ das famílias, além de outras $12 \%$ que a filtravam regularmente. A disponibilidade hídrica para a produção foi identificada com boa ou ótima por $60,7 \%$ e como ruim e péssima para $22,9 \%$ na região, levando em conta que $79 \%$ não utilizavam qualquer sistema de irrigação. A contribuição da agência de ATER para aprimorar o abastecimento e tratamento da água foi apreciada como boa ou ótima por 8,6\% dos assentados, contra 7,2\%, $75,5 \%$ e $8,6 \%$ que as indicavam como insuficientes, ruins ou prejudiciais, respectivamente. Entre os técnicos extensionistas, 69,7\% avaliaram as ações realizadas como boas ou ótimas, contra $21,43 \%$ que as consideravam insuficientes e $8,9 \%$ como nulas.

No Norte do Paraná, predominava o abastecimento diretamente de rios e córregos $(89,7 \%)$ e, minoritariamente, açudes $(4,4 \%)$, poço cacimba $(2,9 \%)$ e nascentes $(2,14 \%)$. Práticas como filtragem, cloração e fervura foram mencionadas, respectivamente, por $8,5 \%, 7 \%$ e 2,8\% dos assentados, prevalecendo $81,7 \%$ de casos nos quais não há qualquer tratamento. A disponibilidade de recursos hídricos para a produção foi apontada como boa ou ótima para $72,5 \%$ e como ruim ou péssima para $18,8 \%$, em um contexto no qual 88,7\% dos entrevistados não contava com qualquer sistema de irrigação. As ações de ATER para aperfeiçoar o acesso aos recursos hídricos foram estimadas como boas ou ótimas por $11,4 \%$, como insuficiente por $2,8 \%$, nulas por $71,4 \%$ e prejudiciais por $14,3 \%$. A pesquisa de campo evidenciou também que $81,5 \%$ dos assentados no Norte do Paraná consideravam que os cursos d'água nos assentamentos não estavam poluídos, contra 14,8\% que caracterizavam rios, córregos e riachos como "pouco poluídos" e 3,7\% como "muito poluídos". No Pontal do Paranapanema, os cursos d'água não vinham sendo caracterizados como poluídos por $69,12 \%$ dos assentados; $16,18 \%$ consideravam os cursos d'água nos assentamentos como "pouco poluídos" e 14,71\% como "muito poluídos".

No norte do Paraná, cerca de um terço dos assentados não identificou processos erosivos em seus lotes no ano base da pesquisa, 2010. Já no Pontal do Paranapanema, os assentados que afirmaram ter verificado problemas de erosão em seus lotes foram praticamente o dobro: 64\% do total. Este problema vinha se acentuando nos últimos anos na percepção de 40,9\% dos assentados no Norte do Paraná e de 22,5\% no Pontal do Paranapanema, contra $25,8 \%$ e $13,0 \%$, respectivamente, que consideravam que o problema vinha sendo reduzido em seus lotes nos anos anteriores. Para os técnicos do Itesp, 40\% consideravam que os casos de erosão vinham sendo reduzidos e $32 \%$ que vinham se acentuando. 
Os assentados que não identificavam assoreamento nos cursos d'água nos assentamentos chegou a 50\% no Norte do Paraná e a 72,1\% no Pontal do Paranapanema. Um total de $28,8 \%$ dos assentados no Norte do Paraná e $17,44 \%$ notaram assoreamentos de baixa ou média intensidade, além de $21,2 \%$ que consideravam que havia intenso assoreamento no assentamento. No Pontal do Paranapanema, casos graves de assoreamento foram relatados por $10,5 \%$ dos assentados e por $17,9 \%$ dos extensionistas do ITESP na região. No entanto, enquanto apenas $17,5 \%$ dos assentados apontaram para a existência de casos leves ou moderados de erosão nos assentamentos, este índice chegou na pesquisa a $71 \%$ dos extensionistas. Para quase $90 \%$ dos extensionistas, portanto, os assentamentos apresentavam algum grau de assoreamento.

A pesquisa buscou levantar informações sobre a perspectiva temporal sobre o tema e com isso foi possível estimar que o assoreamento se afigurava como uma tendência declinante para $16,4 \%$ dos assentados no Norte do Paraná e para 19,4\% no Pontal, além de $21,4 \%$ dos extensionistas do Itesp. Por outro lado, $34,6 \%, 41,9 \%$ e $28,6 \%$, respectivamente, consideravam que vinha ocorrendo uma intensificação de processos erosivos nos assentamentos.

As ações das agências de ATER para a redução da erosão e do assoreamento foram avaliadas como excelentes por apenas $1,56 \%$ no Norte do Paraná e por $0,88 \%$ no Pontal do Paranapanema; e consideradas boas por $6,25 \%$ dos assentados no Norte do Paraná e por 6,19\% no Pontal do Paranapanema. Predomina largamente a indicação de que as ações de ATER para esta finalidade foram nulas: 75\% no Norte do Paraná e 72,57\% no Pontal do Paranapanema, além de $15,7 \%$ e 13,3\%, respectivamente, que as consideraram prejudiciais.

\section{ArborizaÇÃo do ESPAÇO HABITADO}

Entre assentados e técnicos, a arborização nos lotes dos assentamentos é considerada ótima/ideal por 46,5\% e 51,5\%, respectivamente, dos assentados no Norte do Paraná e no Pontal do Paranapanema, opinião expressa por $10,9 \%$ dos extensionistas do ITESP no Pontal, ou seja, por aproximadamente metade dos assentados e por um pequeno grupo de extensionsitas. Diferentemente, para 52,7\% dos assentados no Norte do Paraná e 46,97\% no Pontal do Paranapanema, bem como para 87,27\% dos extensionistas do ITESP na região, a arborização dos lotes onde viviam ou com os quais trabalhavam precisaria ser ampliada.
Já a arborização das áreas comuns nos assentamentos era considerada como ótima/ideal por $52,2 \%$ dos assentados no Norte do Paraná e por $37,6 \%$ no Pontal do Paranapanema, sendo esta também a avaliação de $10,71 \%$ dos técnicos do Itesp. A necessidade de ampliação da arborização nas áreas de uso comum foi apontada por 61,6\% e 52,24\% dos assentados das duas regiões, respectivamente, e por 89,29\% dos técnicos do ITESP no Pontal do Paranapanema. Predomina, portanto, a indicação de ações para o aprimoramento da arborização tanto do interior dos lotes como das áreas comuns nas duas regiões.

As ações de ATER com a finalidade de melhorar a arborização dos assentamos foram estimadas como excelentes ou boas por 20,6\% e 13,4\% dos assentados, respectivamente, do Norte do Paraná e do Pontal do Paranapanema, interpretação compartilhada por 38,19\% dos extensionistas do ITESP no Pontal. Os que consideravam nulas as ações de ATER para arborização somavam 61,8\% dos assentados no Norte do Paraná e 70,9\% no Pontal do Paraná. Outras informações sobre a percepção de assentados e extensionistas sobre arborização dos assentamentos nas duas regiões pesquisas podem ser observadas na Tabela 13.

Tabela 13 - Avaliações de assentados e extensionistas sobre ações de ATER para melhorar a arborização nos assentamentos (2010).

\begin{tabular}{lccccll}
\hline & $\mathrm{N}$ & Excelentes & Boas & Insuficientes & Nulas & Prejudiciais \\
\hline Assentados no Norte PR & 68 & 1,47 & 19,12 & 1,47 & 61,76 & 16,18 \\
Assentados no Pontal & 134 & 1,49 & 11,94 & 4,48 & 70,90 & 11,19 \\
Técnicos do Itesp no & 55 & 3,64 & 34,55 & 52,73 & 9,09 & - \\
Pontal & & & & & & \\
\hline
\end{tabular}

Fonte: Pesquisa de Campo, 2011.

Predomina entre assentados e extensionistas a percepção de que há a necessidade de se aperfeiçoar a arborização dos lotes familiares das áreas comuns nos assentamentos, ao passo que as iniciativas das agências de ATER nas duas regiões, no entanto, são avaliadas como boas ou excelentes por $20,6 \%$ no Norte do Paraná e por $13,4 \%$ no Norte do Paraná.

\section{CONSIDERaÇões Finais}

Os processos de desenvolvimento rural envolvendo a agricultura 
familiar e agrária passam por uma contínua recomposição da qualidade ambiental e do espaço habitado. As condições habitacionais, aliadas à estrutura de saneamento básico, às formas de gestão de resíduos e uso de recursos hídricos, entre outros aspectos, como a arborização, contribuem de forma decisiva para a qualidade de vida no campo. A pesquisa de campo realizada nos assentamentos das regiões do Norte do Paraná e do Pontal do Paranapanema sobre estes aspectos permite evidenciar alguns dos limites e contradições dos processos de gestão ambiental - e permite evidenciar a complexidade territorial e ambiental dos processos de desenvolvimento rural.

No que se refere à gestão de resíduos, foi constatado que a maioria dos assentados vinha queimando e enterrando resíduos recicláveis, tais como plástico, papel, vidro e metais, juntamente com pilhas, baterias e rejeitos não recicláveis. Por outro lado, apenas $7 \%$ dos assentados pesquisados no Norte do Paraná e 4\% no Pontal do Paranapanema estimaram como boas ou ótimas as ações de extensão rural oficial para aprimorar a gestão de resíduos. No mesmo sentido, 78\% dos técnicos extensionistas da Fundação Itesp no Pontal do Paranapanema consideravam insuficientes ou nulas as ações realizadas para a gestão de resíduos.

A percepção de assentados e técnicos para a gestão de recursos hídricos e para a arborização do espaço habitado segue um perfil bastante semelhante, predominando um contraste ente a situação ambiental vivenciada nos assentamentos e as ações de ATER visando o equacionamento destes problemas. Este quadro aponta para a importância de um aprimoramento da pauta ambiental nas agências prestadoras de serviços oficiais de extensão rural, bem como para a relevância da produção de estudos quantitativos de percepção como parte dos instrumentos voltados para a caracterização dos problemas ambientais e de sua discussão pública, algo que contribui para fomentar o conhecimento, o envolvimento e a participação de diversos atores locais.

Verifica-se uma demanda reprimida em relação à questão ambiental junto às populações aqui estudadas. Por se tratar, em grande medida, de um componente educativo, uma abordagem multidisciplinar desta problemática deve permear o debate, no sentido de construir alternativas de atuação nestes territórios. Neste sentido, a atuação da ATER apresenta um grande potencial a ser explorado, principalmente se construir vinculações e programas comuns de ação com outros agentes do poder público local e regional, principalmente das áreas de educação, saúde e meio ambiente.

\section{REFERÊNCIAS}

BARONE, L. A, FERRANTE, V.L.B. (2012), Assentamentos rurais em São Paulo: estratégias e mediações para o desenvolvimento. Dados, 55(1): 755-785.

BONNAL, P., MALUF, R. (2009), Políticas de desenvolvimento territorial e multifuncionalidade da agricultura familiar no Brasil. Política \& Sociedade, v. 8, n. 14 , p. $211-250$.

BRANDENBURG, A. (2004), Sócio-ambientalismo e novos atores na agricultura. In: CALZAVARA, O. E R. O. LIMA (org.), Estratégias para um desenvolvimento rural de inclusão. Londrina: Eduel (Universidade Estadual de Londrina).

CECilio, M. A; PUZIOL, J. K. P., SilvA, I. M. S. (2010), A Espacialização da Educação do Campo no Paraná: uma forma de resistência do MST. Teoria e Prática da Educação, vol. 3, n. 2, p. 213-222.

COSTA, R.C., FUTEMMA, C.R. (2006), Racionalidade com compromisso: os assentados do Ribeirão Bonito (Teodoro Sampaio - SP) e o projeto de conservação ambiental. Ambiente \& Sociedade, vol. , nº. 1, p. 127-148.

CUNHA, L.H.; NUNES, A.M.B. (2008), Proteção da natureza e conflitos ambientais em assentamentos rurais. Desenvolvimento e Meio Ambiente, v. 18, p. $27-38$.

HUYLENBROECK, G., DURAND, G, org. (2003), Multifunctional agriculture: a new paradigm for European agriculture and rural development, Aldershot: Ashgate

INCRA (2010). Instituto Nacional de Colonização e Reforma Agrária. Pesquisa sobre Qualidade da Reforma Agrária (PQRA/INCRA). Brasília: Instituto Nacional de Colonização e Reforma Agrária

IPARDES (2013). Indicadores de desenvolvimento sustentável por bacias hidrográficas do estado do Paraná. Curitiba: IPARDES (Instituto 
Paranaense de Desenvolvimento Econômico e Social).

LEFF, E. (2009), Ecologia, capital e cultura. A territorialização da racionalidade ambiental, Petrópolis: Vozes.

MARIN, A. A. (2008) Pesquisa em educação ambiental e percepção ambiental. Pesquisa em Educação Ambiental, vol. 3, n. 1, p. 203-222.

MIOR, L. C. (2003), Agricultores familiares, agroindústrias e território: a dinâmica das redes de desenvolvimento rural no Oeste catarinense. Florianópolis: Universidade Federal de Santa Catarina. Tese de Doutorado.

NORDER, L., URSI, M.V. (2013), Indicadores sobre vinculações institucionais entre assentados no Norte do Paraná e no Pontal do Paranapanema. Retratos de Assentamentos, vol. 16, p. 43-57.

NORDER, L., URSI, M.V., MENEZES JR, A., RODRIGUES, D.D. (2015), Percepção social sobre florestas nativas e restauração ecológica em assentamentos rurais no Pontal do Paranapanema e Norte do Paraná.

Campo Território, vol. 10, n. 20, p. 538-557.

NORDER, L., URSI, M.V. (2017), Percepção social sobre transição agroecológica e extensão rural em assentamentos no Norte do Paraná e no Pontal do Paranapanema. Espacios, vol. 38, p. 15-32, 2017.

PLOEG, J.D. (2006), O modo de produção camponês revisitado. In: Schneider, S. (org.), A diversidade da agricultura familiar. Porto Alegre: Ed. UFRGS, pp. 13-54.

RODRIGUES, M. L. et al. (2012), A percepção ambiental como instrumento de apoio na gestão e na formulação de políticas públicas ambientais. Saúde e Sociedade. São Paulo, v. 21, supl. 3, p. 96-110.

SANTOS FILHO, A. (1980), As principais consequências do desmatamento e o uso do solo no Estado do Paraná. Floresta, vol. 11, pág. 12-16.

SCHIAVINATTO, F. (org.) (2011), Sistema de Indicadores de Percepção
Social (SIPS). Brasília: Instituto de Pesquisa Social Aplicada, 254p.

TSUKAMOTO, R.Y., ASARI, A.Y. (2003), Assentamentos rurais e agricultura familiar: processo de territorialização e perspectivas de autosustentação. Geografia, Volume 12, Número 1, p. 483-494, Jan/Jun. 2003.

VALENTE, S.; FIGUEIREDO, E.; COELHO, C. (2008), Entre os riscos e os benefícios - análise da percepção social do risco em duas comunidades mineiras. Anais do VI Congresso Português de Sociologia, Lisboa, de 25 a 28 de junho de 2008 .

WANDERLEY, M. N. B. (2001), A ruralidade no Brasil moderno: por um pacto social pelo desenvolvimento rural. In: GIACARRA, N. (org.), Uma nueva ruralidad en America Latina? Buenos Aires: Clacso/ASDI. 